\title{
A Fuzzy Supplier Selection Application Using Large Survey Datasets of Delivery Performance
}

\author{
Jonathan Davis, Margaret F. Shipley, and Gary Stading \\ The University of Houston-Downtown, 326 N Main Street Houston, TX 77002, USA \\ Correspondence should be addressed to Jonathan Davis; davisg@uhd.edu
}

Received 27 August 2014; Revised 10 October 2014; Accepted 13 October 2014

Academic Editor: Ferdinando Di Martino

Copyright (c) 2015 Jonathan Davis et al. This is an open access article distributed under the Creative Commons Attribution License, which permits unrestricted use, distribution, and reproduction in any medium, provided the original work is properly cited.

\begin{abstract}
A model is developed using fuzzy probability to screen survey data across relevant criteria for selecting suppliers based on fuzzy expected values. The values are derived from qualitative variables and expert opinion of membership in these variables found in industry survey data. The application is made to a supply chain management decision of supplier selection based upon delivery performance which is further divided into attributes that comprise this criterion. The algorithm allows multiple criteria to be considered for each decision parameter. Large sets of survey data regarding six suppliers in the electronic parts industry are gathered from over 150 purchasers and are analyzed through spreadsheet modeling of the fuzzy algorithm. The resulting decision support system allows supply chain managers to improve supplier selection decisions by applying fuzzy measures of criteria and associated beliefs across the dataset. The proposed model and method are highly adaptable to existing survey datasets, including datasets that have incomplete data, and can be implemented in organizations with low decision support resources, such as small and medium sized organizations.
\end{abstract}

\section{Introduction}

Selecting suppliers has become an area of increasing study due to its importance for establishing long-term channel relationships. Firms have become highly selective of their suppliers but suffer in this process because existing evaluative measures often do not rank suppliers on a relative basis. Thus, of importance is that the firm be able to identify suppliers through an effective evaluation process [1]. Yet this supplier selection evaluation process is a complex decision space with overlapping, complementary, and often contradictory selection criteria. Coupled with the ambiguity in selection criteria, uncertainty in such a decision exists since all relevant attributes may not be identified or even identifiable.

Many factors contribute to the difficulty of rank ordering in the supplier evaluation process. Selection criteria and scoring can occur at various levels of the organization, which leads to conflicts in scoring, particularly in systems built to reflect qualitative criteria. Assessors operating in these systems often experience inherent uncertainty regarding supplier performance due to lack of a proper anchoring or definition of numerical scores. This ambiguity means that a supplier's score on a criterion may not be determinant. Assessors rely on statistical analysis that provides the highest probability of achieving a qualitatively defined membership, yet membership of a supplier in the category of "good," for example, may vary in opinion over time and by different assessors.

Scoring models have been used in various aspects of supply chain management for many years because supplier selection lends itself to models incorporating management opinion $[2,3]$. However, decision support systems can benefit from improvements that bring clarity to otherwise vague scoring criteria [4-6], because such improvements enlarge the available sets of useful data these systems can use. Given the benefit of using expert judgment from management and professionals, a fuzzy set based model that has a proven record of handling uncertainty of the decision maker and ambiguity of data while allowing these experts to assess membership across several criteria can be an effective evaluation tool.

Indeed, extant methods that use classical logic or statistics have been shown to be inadequate for effectively dealing with situations where limited information is available. Behavioral 
and expected utility theorists have argued that probability theory and other traditional quantitative techniques are not equipped to consider the uncertainty that exists in most personal judgments $[7,8]$. Among alternative techniques, the Dempster-Shafer theory of evidence [9-12] provides useful measures for the evaluation of subjective certainty. Fuzzy set theory is among the most powerful tools for dealing with uncertainty where ambiguous terms are present [13-16]. Of particular interest to the development of the algorithm and the ensuing application are fuzzy probability distributions [17] and the concept of fuzzy expected values [18].

This research furthers the use of fuzzy logic models in supplier selection decisions. Background information is presented relative to traditional supplier selection methods and the general advancement of fuzzy logic-based models into supply chain management with more recent models targeting supplier selection decisions. Additional background literature is presented that identifies the traditional criteria for supplier selection. Next, fuzzy logic notation and model development lead to a spreadsheet application based on a survey of responses from a sample of professional buyers. Guidelines are introduced to resolve problems with the dataset regarding data insufficiency and/or incomplete responses, and the dataset is filtered to create a subset of the original dataset that is sufficiently populated with data. Results are then presented and analyzed.

\section{Materials and Methods}

As noted in the introduction, supplier selection decisions are receiving increasing focus in industry, and the associated academic papers have no shortage of ideas about how selection decisions can be made. Alternatives range from simple expert opinion methods that are not reliably repeatable to quantitative methods that may not account for various criteria associated with standards for supplier performance.

2.1. Supplier Selection Models. Recent supplier selection models have focused on using the analytic hierarchy process (AHP) or providing case study illustrations of decision making processes utilizing expert opinions [19-21]. Measuring the performance of suppliers [1] and stressing the importance of supplier selection criteria [2] for small firms in the United States [22] or large firms in Japan [23] reinforce that this initiative is not restricted to large firms and is global. Typical criteria used are price, delivery, and quality (PDQ) $[1,23]$ but Park and Krishnan [22] add several managerial criteria beyond PDQ including managerial forecasts, trust level, and organizational structure. Supplier selection research using decision support systems also extends supplier selection criteria in other dimensions including environmental considerations [6]. Weber et al. [24] considered other factors like facility location, capacity, and financial position. Ellram [25] discussed the importance of incorporating these and other decision criteria in the process of selecting suppliers, and Simpson et al. [1] provide an extensive study of criteria perceived as most crucial to the assessment.

Using the traditional PDQ criteria, Verma and Pullman [26] provide an extensive study of how purchasing managers evaluate trade-offs among the criteria. They point out that while the PDQ criteria are generally accepted in industry, delivery and quality lend themselves to decision support criteria models because the complexity and multiple dimensions of delivery and quality can confound a decision maker. Of these criteria, quality tends to be extensively studied by researchers [21], while supplier selection and evaluation are most often based entirely on price $[27,28]$. Thus, by elimination, delivery does not have nearly the research support.

In response to this dearth of research and in recognition of the global importance of supplier selection, four separate focus groups representing international and national geographical areas were used to identify attributes of delivery that would confound a purchasing decision. While many attributes were identified by the focus groups, those used for the "delivery" example in this study include the following: inventory availability, on-time deliveries, shipping accuracy, and a supplier's receptiveness to authorizing material returns (RMAs), as supported by Simpson et al. [1]. Given the previous justification of delivery as the focus criterion for this project with support by Vahdani and Zandieh [29] as to the strength of fuzzy set theory and outranking methods relative to the other decision support methodologies, fuzzy logic appeared appropriate for supplier selection decisions.

2.2. Fuzzy Logic in Supply Chain Management. As early as 1999, Liu [30] proposed a fuzzy model for partial backordering models. Little was done with inventory considerations until fully five years later when inventory discounting considered the buyer-seller relationships [31], and location aspects for inventory control became fuzzy considerations [32]. Supply chain decisions for integrated just-in-time inventory systems recognized the fuzzy nature of annual demand and production rates as being no longer statistically based. The supposition of known annual demand was considered by the authors to be unrealistic such that the proposed model included fuzzy annual demand and/or production rate, employing the signed distance, a ranking method for fuzzy numbers, to estimate fuzzy total cost of the JIT production in today's supply chain environment. A fuzzy-set based method derived the optimal buyer's quantity and number of lots from the vendor [33].

Some fuzzy set-based decision-making models appeared when fuzzy programming was used for the following: optimal product mix based on $\mathrm{ABC}$ analysis [34]; fuzzy multiobjective linear programming minimized total production and transportation costs; the number of rejected items and total delivery time as related to labor and budget constraints [35]; and fuzzy goal programming considered supply chain management from the perspective of activity-based costing with mathematically derived optimization for evaluating performance of the value-chain relationship [36]. Manufacturing processes as related to business logistics looked at the data itself as fuzzy in Quality Function Deployment's relationship to customer service [37]. The attainment of goals such as quality further led to attempts to balance production processes of assembly lines. Fuzzy goals were used as an instrument and product for measuring, displaying, and controlling industrial process variables [34]. 
Considering different quality standards in a supply chain network a fuzzy neural approach was utilized to suggest adjustments of product quantity from various suppliers [38]. The Fuzzy Suitability Index (FSI) aggregated rankings and multiplied, by weight, each criterion [39]. With the same goal of ranking suppliers according to performance, a method was proposed whereby $n$ decision makers evaluated the performance of $m$ suppliers in $k$ criteria, rating the importance of the $k$ criteria in linguistic terms. Aggregation of the fuzzy expressions for importance weights and a fuzzy preference index led to rank ordering of the suppliers [40].

Supplier selection was developed from a rule-based perspective. The approach selected was fuzzy associated rule mining from the database for supplier assessment [14]. Sevkli [41] in a comparison of a recognized crisp ELECTRE model versus a fuzzy ELECTRE model reached the conclusion that using fuzzy sets for multicriteria supplier selection decisions is superior.

2.3. Theory. The model developed herein uses fuzzy set theory and extension principles with fuzzy probabilities that determine a belief-weighted score for each attribute of each criterion. A revision to an existing algorithmic process [12] is defined with presentation and justification specific to this supplier selection decision-making problem based upon delivery attributes.

2.3.1. Fuzzy Logic Approach. Fuzzy logic addresses the ambiguity of data and uncertainty in this decision making situation, where a fuzzy subset $A$ of a set $X$ is a function of $X$ into $[0,1]$. For a brief foundation in the basics, see Zadeh [42], Bellman and Zadeh [13], Dubois and Prade [43], and Freeling [44]. While a new class of implication operators has been proposed [45], the more traditionally utilized fuzzy operations are used in this research. $A$ and $B$ denote two fuzzy sets, so the intersection, union, and complement are defined by

$$
\begin{gathered}
A \cap B=\sum \frac{\gamma_{i}}{x_{i}}, \quad \text { where } \gamma_{i}=\operatorname{Min}\left\{\alpha_{i}, \beta_{i}\right\} ; \\
A \cup B=\sum \frac{\gamma_{i}}{x_{i}}, \quad \text { where } \gamma_{i}=\operatorname{Max}\left\{\alpha_{i}, \beta_{i}\right\} ; \\
\neg A=\sum \frac{\gamma_{i}}{x_{i}}, \quad \text { where } \gamma_{i}=1-\alpha_{i} ;
\end{gathered}
$$

and it is assumed that $B=\sum \beta_{i} / x_{i}[46-49]$.

Extension principles $[18,43,50]$ often guide the computations when dealing with fuzzy sets. Letting $f$ be a function from $X$ into $Y$, with $Y$ as any set and $A$ as above, then $f$ can be extended to fuzzy subsets of $X$ by

$$
f(A)=\sum_{y} \frac{u_{f(A)}(y)}{y}, \quad \text { where } u_{f(A)}(y)=\operatorname{Max}_{x \varepsilon f^{-1}(y)} A(x) .
$$

Thus, $f(A)$ is a fuzzy subset of $Y$. In particular, if $f$ is a mapping from a Cartesian product such as $X \times Y$ to any set,
$Z$, then $f$ can be extended to objects of the form $(A, B)$ where $A$ and $B$ are fuzzy subsets of $X$ and $Y$ by

$$
\begin{gathered}
f(A, B)=\sum \frac{u_{f(A, B)}(z)}{z}, \\
\text { where } u_{f(A, B)}(z)=\operatorname{Max}_{(x, y) \varepsilon f^{-1}(z)} \operatorname{Min}\{A(x), B(x)\} .
\end{gathered}
$$

A fuzzy set $P$ whose elements all lie on the interval $[0,1]$ can be expressed as a fuzzy probability.

2.3.2. Fuzzy Probability Distributions. Consider a set of $n$ fuzzy probabilities each having $r$ elements,

$$
a_{i}=\sum_{j=1}^{r} \frac{\alpha_{i j}}{a_{i j}} \quad \text { for } i=1,2, \ldots, n,
$$

where $\alpha_{i j}$ denotes the degree of belief that a possible value of $a_{i}$ is $a_{i j}$. Then $\left(a_{1}, a_{2}, \ldots, a_{n}\right)$ constitutes a finite fuzzy probability distribution if and only if there are $n$-tuples $a_{i}, i=1,2, \ldots, n$, such that $\sum_{i=1}^{n} a_{i}=1$.

To qualify as a finite fuzzy probability distribution, each fuzzy probability in the distribution must have the same number of elements (some of the $a$ 's may be zero), and these elements should be ordered in the sense that the sum of the elements in each specific position must equal one. So the $n$ tuples $\left(a_{i j}\right), i=1,2, \ldots, n$, form probability distributions in the crisp sense. This type of probability distribution can be transformed such that the resulting distribution has entropy at least as great as the original [17].

2.3.3. Fuzzy Expected Value. A version of fuzzy expected values was first used when Zebda [18] defined $Q_{i j k}=\sum \alpha_{i j k} /$ $a_{k}$ as the fuzzy probability that, from State $i$ and making Decision $j$, reaches State $k$. Associated with this are fuzzy benefits $B_{i j k}$, where $B_{i j k}=\sum \beta_{i j k} / b_{k}^{\prime}$. where

Then the averaged benefit is defined by $E\left(B_{i j k}\right)=\sum c_{i j \ell} / b_{\ell}$

$$
\begin{aligned}
& c_{i j e}=\underset{\left(a_{1}, \ldots, a_{p}, b_{1}^{\prime}, \ldots b_{p}^{\prime}\right) \varepsilon f^{-1} b_{\ell} k}{\operatorname{Min}}\left(\alpha_{i j k}, \beta_{i j k}\right) \\
& \text { for } b_{\ell}=\sum_{k} a_{x} b_{x} \text { if } \sum_{k} a_{x}=1 \text { and } 0 \text { otherwise. } \\
& \text { Here, } f\left(a_{1}, \ldots, a_{p}, b_{1}^{\prime}, \ldots, b_{p}^{\prime}\right)=\sum a_{x} b_{x}^{\prime} \text {. }
\end{aligned}
$$

2.3.4. Fuzzy Supplier Selection. In an earlier pilot study application [51], a fuzzy probability-based algorithm demonstrated a decision model based on a single rating for each supplier. But suppliers are usually not scored by only one kind of criterion, the attributes of which may vary in importance from one customer to another. Also, the application abbreviated the decision space considerably by disallowing suppliers that scored Below Average on an attribute, which works well for a single-attribute example but breaks down when applied across many attributes or criteria in a large dataset.

The proposed fuzzy algorithm recognizes that a supplier could score Below Average on an attribute that is relatively 
unimportant to the customer but still be rated highest overall if the supplier's other scores are sufficiently high in areas of greater importance to the customer. Since the many respondents are not equally confident in the scores they give, the algorithm makes use of the value of fuzzy probability with respect to each supplier measure and limits the discarding of a great deal of valuable data.

2.4. Algorithm. The algorithm preserves information during the process of computing and evaluating fuzzy probabilities until a final weighted model collapses the results into an objective score.

(0) Randomly partition the criteria dataset into $\ell$ subsets of equal size.

(1) For each attribute $\phi$ of each supplier $\nu$, subjectively assign scores $s_{\phi k \nu}$. The supplier rating $\left(s_{\phi k \nu}\right)$ is then given by the equation $s_{\phi k \nu}=\sum \tau_{\phi k} / s_{\phi k}$ for all $\nu$ where $\tau_{\phi k}=1(\nu=1,2, \ldots, m ; k=1,2, \ldots, n$; and $1<\phi<$ $x)$.

(2) Define the fuzzy expected value, $Q_{\phi k v}$, for each attribute $\phi$ of each $v$ in terms of each $s_{\phi k \nu}$ as $Q_{\phi k j v}=$ $\sum \alpha_{\phi k j v} / a_{\phi k j v}$ for all $s_{\phi k j v}$, where each $\alpha_{\phi k j v}$ represents belief in the probability $a_{\phi k j}$ that $\nu$ will be scored $s_{\phi k j v}$ $(\nu=1,2, \ldots, m ; k=1,2, \ldots, n ; 1<\phi<x$ and $j=1,2, \ldots, \ell)$.

(3) Group the probabilities $a_{\phi k j v}$ into combinations $\varphi_{\phi v}$ such that $\sum a_{\phi k j v}=1$ for some set $H$ of $k$ 's. $a_{\phi k j v}=0$ for $k \notin H$.

(4) Across all partitions $\ell$, compute $b_{\phi v}=\sum a_{\phi k j v} s_{\phi k j v}$ if $\sum a_{\phi k j v}=1$, otherwise $0(k=1,2, \ldots, r ; j=1,2, \ldots, \ell$ and $p=$ the distinct number of $\sum a_{\phi k j v}=1 ; 1<\ell \leq$ p).

(5) For all $\alpha_{\phi k j v} \neq 0$ find $c_{\phi v}=\operatorname{Min}\left\{\tau_{\phi k j v}, \alpha_{\phi k j v}\right\}$, where $c_{\phi v}$ is the degree of belief that the expected value is $b_{\phi v}$.

(6) Defuzzify the expected value for each attribute $\phi$ to find $E\left(s_{\phi v}\right)=\sum c_{\phi v} b_{\phi v} / \sum c_{\phi v}$.

An illustration of this supplier selection modeling algorithm is presented next.

2.5. Algorithm Methods and Illustration. The application presents a real-world supplier selection decision-making problem based upon (1) generation of data from a survey of purchasing professionals and (2) partitioning of the resulting data to fit the algorithm detailed above.

2.5.1. Example Data. The algorithm example uses results from a survey instrument built with input from industry expert focus groups. The subsequent survey measures customer ratings of a group of suppliers for various variables including delivery attributes. The survey was distributed to about 3,000 companies that purchase semiconductors, passives, $\mathrm{RF} /$ microwaves, connectors and interconnects, and electromechanical devices from a small set of dominant suppliers. Representative industries included automotive, communications, contract design/engineering, power/electrical, medical/dental, computer, manufacturing, and military/aerospace. The survey queried each customer's number of years of activity in the industry in designated ranges from less than two to 21 or more. Customers dealt with multiple suppliers and specified their firm's annual sales revenue as under $\$ 5,000,000$ to over $\$ 2,000,000,000$. With 406 surveys received, the response rate was slightly under $15 \%$.

The survey was scored on a $0-5$ Likert scale for seven suppliers: Arrow, Avnet, Future, Insight, Kent, Pioneer, and TTI. Respondents used the same scale for satisfaction with each supplier individually on the service performance attributes.

For model application purposes, the survey provided performance measurements on each supplier, as well as measures of the importance of each criterion to the customer and the customer's level of belief explicitly tied to the company's annual amount of business conducted with the targeted group of suppliers. Survey questions relating directly to the importance of this fuzzy supplier selection application included a query of the amount of money the customer spends on electronic components in a year: $<\$ 100,000$; $\$ 100,000-\$ 499,999 ; \quad \$ 500,000-\$ 999,999 ; \quad \$ 1,000,000-$ $\$ 9,999,999 ; \$ 10,000,000-\$ 24,999,999 ;$ and $>\$ 25,000,000$. These ranges were used to identify a firm's level of activity with the suppliers in question and, therefore, its expected level of confidence (interpreted as belief) in its assessments.

Given that real-world collection of survey data is, to varying degrees, imperfect, a threshold (10 data points) was established beyond which a respondent's data cluster would be considered too incomplete and removed. Furthermore, one supplier, Kent, was removed from the set due to (a) low survey responses compared to the other suppliers and (b) no longer existing as an independent company, having been acquired by Avnet after the survey was conducted. The resulting dataset left a pool of 150 responses considered "useable" to be applied to the fuzzy algorithm. These responses each had between 0 and 10 missing data points, which correspond to individual survey questions that went unanswered by the respondent. It is necessary to accept and adapt to this imperfect data in order to have a sufficiently large dataset to draw useful conclusions, given the nature of survey data.

The 150 acceptable survey responses resulting from the filtering of the data from the original 406 surveys were randomly partitioned into two sets of 75 responses each in accordance with Step 0 of the model algorithm. These respondents evaluated suppliers on the delivery-specific attributes: on-time performance, availability of inventory, shipping accuracy, and RMAs.

2.5.2. Fuzzy Preference Algorithm. Using the partitioned datasets provides two inputs into the defined fuzzy probability distributions.

By Step 1 of the algorithm, $\phi=1,2,3,4$ attributes as defined above. Each of the four attributes is subjectively assigned a score by the respondent for each of the six suppliers $(m=6)$, equating to Poor, Below Average, Average, Above Average, and Excellent $(n=5)$. Supplier rating $s_{\phi v}$ is then 
given by the equation $s_{\phi v}=\sum \tau_{\phi k \nu} / s_{\phi k \nu}$ for each supplier, $v$, and, by Step 2, the fuzzy probability $Q_{\phi k j v}$ for each attribute of $v$ in terms of $s_{\phi k j v}$ is $Q_{\phi k j v}=\sum \alpha_{\phi k j v} / a_{\phi k j v}$ for all $s_{\phi v}$. Each $\alpha_{\phi k j v}$ represents belief in the probability $a_{\phi k j v}$ that $v$ will perform to the level of the assigned score $s_{\phi v}(k=1,2, \ldots, 5$; $v=1,2, \ldots, 6 ; \phi=1,2,3,4$; and $j=1,2$ ).

The belief functions were populated based on a survey question indicating the amount of annual spending done by the respondent. Table 1 describes the scoring of respondent belief as proportional to total possible spending (conservatively assumed to be the low end of the top category, $\$ 25,000,000)$ as shown in Table 1 .

Beliefs were assigned for each respondent according to Table 1 and averaged across all respondents for each rating. After the assignment of belief, the algorithmic process for supplier $v$ shows four significant digits to make the method clear, although subsequent suppliers are rounded to two significant digits for readability and brevity. $Q_{\phi k \nu}$ is as follows:

$$
\begin{array}{r}
Q_{111}=0.0000 / 0.0000+0.2500 / 0.0400 \\
\text { for } s_{\phi k v}=s_{111}=\operatorname{Poor}(1) \\
Q_{121}=0.1100 / 0.0533+0.3400 / 0.0800 \\
\text { for } s_{121}=\text { Below Average }(2) \\
Q_{131}=0.3900 / 0.2267+0.3800 / 0.2133 \\
\text { for } s_{131}=\text { Average }(3) \\
Q_{141}=0.3000 / 0.6133+0.3500 / 0.3600 \\
\text { for } s_{141}=\text { Above Average }(4) \\
Q_{151}=0.2200 / 0.1067+0.1900 / 0.3067 \\
\text { for } s_{151}=\text { Excellent }(5) .
\end{array}
$$

For Arrow, $s_{\phi v}=1.0 / 1+1.0 / 2+1.0 / 3+1.0 / 4+1.0 / 5$.

In the case of 0.0 beliefs, the estimation of no likelihood (0.0) that the supplier's on-time delivery will rate Poor is because no respondents in partition one scored this supplier as Poor. Since one respondent in partition two did rate the company's delivery performance as Poor, and this respondent's sales revenue volume was in the middle range, there is a 0.51 belief that there is a 0.04 probability that Arrow's ontime delivery will be Poor. The highest beliefs ( 0.39 and 0.38 ) are for low probabilities $(0.2267$ and 0.2133$)$ that the supplier has Average on-time performance. The highest probabilities (0.6133 and 0.3600) for Above Average have among the highest beliefs ( 0.3 and 0.35 , respectively). While one group of respondents considered a 0.3067 probability of occurrence with 0.19 beliefs, the other group held an even higher belief for a low probability (0.1067) of Excellence in on-time delivery by Arrow.

Beliefs $\left(\alpha_{\phi k j v}\right)$ and corresponding probabilities $\left(a_{\phi k j v}\right)$ are then defined as

$$
\begin{aligned}
& \alpha_{1111}=0.0000, \\
& \alpha_{1211}=0.1100, \\
& \alpha_{1311}=0.3000, \\
& \alpha_{1411}=0.3000,
\end{aligned}
$$

TABLE 1: Respondent belief associated with spending.

\begin{tabular}{lc}
\hline Spending & Degree of belief \\
\hline$<\$ 100,000$ & 0.0020 \\
$<\$ 500,000$ & 0.0100 \\
$<\$ 1,000,000$ & 0.0300 \\
$<\$ 10,000,000$ & 0.2000 \\
$<\$ 25,000,000$ & 0.7000 \\
$>\$ 25,000,000$ & 1.0000 \\
\hline
\end{tabular}

$$
\begin{aligned}
& \alpha_{1511}=0.2200, \\
& \alpha_{1121}=0.2500, \\
& \alpha_{1221}=0.3400, \\
& \alpha_{1321}=0.3800, \\
& \alpha_{1421}=0.3500, \\
& \alpha_{1521}=0.1900, \\
& a_{1111}=0.0000, \\
& a_{1211}=0.0533, \\
& a_{1311}=0.2267, \\
& a_{1411}=0.6133, \\
& a_{1511}=0.1067, \\
& a_{1121}=0.0400, \\
& a_{1221}=0.0800, \\
& a_{1321}=0.2133, \\
& a_{1421}=0.3600, \\
& a_{1521}=0.3067 .
\end{aligned}
$$

According to Step 3 of the algorithm, all combinations $\varphi_{\phi v}$ of the five scores across both data partitions are considered for each outcome that sums one, which in this example yields

$$
\begin{aligned}
& \varphi_{\phi v 1}=a_{1111}+a_{1211}+a_{1311}+a_{1411}+a_{1511}=1.0 \\
& \varphi_{\phi v 2}=a_{1121}+a_{1221}+a_{1321}+a_{1421}+a_{1521}=1.0 .
\end{aligned}
$$

Possible $n$-tuples are $(0.0000,0.0533,0.2267,0.6133$, $0.1067)$ and $(0.0400,0.0800,0.2133,0.3600,0.3067)$. Following Step 4, a "weighted average" probability $b_{\phi v}$ for all $\varphi_{\phi v}$ is derived

$$
\begin{aligned}
b_{\phi v 1}= & (0.0000)(1)+(0.0533)(2)+(0.2267)(3) \\
& +(0.6133)(4)+(0.1067)(5)=3.7733, \\
b_{\phi v 2}= & (0.0400)(1)+(0.0800)(2)+(0.2133)(3) \\
& +(0.3600)(4)+(0.3067)(5)=3.8133 .
\end{aligned}
$$


The minimum degree of belief in the on-time delivery then assessed according to Step 5 considers only the cases where belief is greater than zero:

$$
\begin{gathered}
c_{\phi \nu 1}=\operatorname{Min}\{0.11,1 ; 0.39,1 ; 0.30,1 ; 0.22,1\}=0.11, \\
c_{\phi \nu 2}=\operatorname{Min}\{0.25,1 ; 0.34,1 ; 0.38,1 ; 0.35,1 ; 0.19,1\}=0.19 .
\end{gathered}
$$

Step 6 defuzzifies the expected score such that $v_{1}$ 's expected fuzzy score for on-time delivery performance is

$$
\begin{aligned}
E\left(s_{11}\right) & =\frac{[(0.1100)(3.7733)+(0.1900)(3.8133)]}{[0.1100+0.1900]} \\
& =3.7987
\end{aligned}
$$

Applying the algorithm (with significant digit rounding) to the second supplier $v_{2}$ (Avnet) yields

$$
\begin{array}{ll}
Q_{112}=0.2 / 0.0+0.4 / 0.0 & \text { for } s_{112}=\text { Poor }(1) \\
Q_{122}=0.4 / 0.1+0.3 / 0.1 & \text { for } s_{122}=\text { Below Average }(2) \\
Q_{132}=0.4 / 0.3+0.4 / 0.3 & \text { for } s_{132}=\text { Average }(3) \\
Q_{142}=0.3 / 0.6+0.3 / 0.4 & \text { for } s_{142}=\text { Above Average }(4) \\
Q_{152}=0.2 / 0.1+0.1 / 0.2 & \text { for } s_{142}=\text { Excellent }(5)
\end{array}
$$

Again, according to Step 3 of the algorithm, all combinations are considered for each outcome that sums one, which in this example yields $a_{\phi k j v}$ combinations:

$$
\begin{aligned}
& \varphi_{\phi v 1}=a_{1111}+a_{1211}+a_{1311}+a_{1411}+a_{1511}=1.0, \\
& \varphi_{\phi v 2}=a_{1121}+a_{1221}+a_{1321}+a_{1421}+a_{1521}=1.0
\end{aligned}
$$

as for supplier $v_{1}$ (Arrow) but also

$$
\begin{aligned}
& \varphi_{\phi v 3}=a_{1111}+a_{1221}+a_{1311}+a_{1411}+a_{1511}=1.0, \\
& \varphi_{\phi v 4}=a_{1111}+a_{1211}+a_{1321}+a_{1411}+a_{1511}=1.0, \\
& \varphi_{\phi v 5}=a_{1121}+a_{1221}+a_{1321}+a_{1421}+a_{1521}=1.0, \\
& \varphi_{\phi v 6}=a_{1121}+a_{1211}+a_{1321}+a_{1421}+a_{1521}=1.0, \\
& \varphi_{\phi v 7}=a_{1121}+a_{1221}+a_{1311}+a_{1421}+a_{1521}=1.0 .
\end{aligned}
$$

At this point, the spreadsheet organizes and solves the equations. The expected values are calculated based upon the algorithmic steps from the following respondent-provided fuzzy probabilities.

2.6. Illustrative Spreadsheet Example. While the algorithmic process is not overly complex, the transitioning of the algorithm into a realistic decision support system (DSS) capable of handling an extensive set of data has many challenges. Due to spreadsheet ease of use and availability to businesses, including small to mid-size enterprises, the focus of the research was to provide a fully functioning spreadsheet-based DSS. The illustration provided shows the resulting complexity of interpreting the algorithm with a standard spreadsheet approach.

An organized layout of the intermediate results of algorithm Steps 1 and 2 was created, as shown in Table 2, where $1 s-$ $5 s$ represent the qualitative variables defined as Poor, Below Average, Average, Above Average, and Excellent, respectively. Question 20 referred to the on-time delivery performance of the suppliers denoted as "a" through "f" for Arrow, Avnet, Future, Insight, Pioneer, and TTI, respectively.

The probability calculation is a simple counting of the number of responses of, for example, "2," divided by a count of the number of responses in the appropriate partition. The function used is as follows:

$$
\begin{aligned}
& =\operatorname{COUNTIF}([\text { cell range of responses }], "=2 ”) / \\
& \operatorname{COUNTIF}([\text { cell range of responses }], ">0 ")
\end{aligned}
$$

The belief calculation relied upon the assumptions stated above and given in Table 1. Accordingly, the belief value for each score (1-5) is calculated using the following formula:

$$
\begin{aligned}
& =\operatorname{SUMIF}([\text { cell range of scores }], "=2 ", \\
& {[\text { cell range of beliefs] }) / \operatorname{COUNTIF}([\text { cell }} \\
& \text { range of scores }], "=2 ")
\end{aligned}
$$

Rounding leads to the two-significant-digit 5-tuples shown in Table 3.

Organizing the 5-tuples into sums of fuzzy probabilities is the next step, according to Step 3 of the algorithm. This was accomplished by creating a row/column spot for every possible combination of every element of every question, as shown in Table 3.

The numbers in Table 3 represent the possible combinations of beliefs summed for Question 20 for suppliers $v_{1}$ through $v_{6} ; 16$ for each data partition per supplier. The shaded cells represent combinations that have fuzzy probabilities that sum 1.0 or that sum very close to 1.0 , within the established threshold. Note that the top and bottom combinations always sum exactly to one since all possibilities are represented by the five scores (1-5) in any given partition.

With the 5-tuples identified that have fuzzy probabilities that sum 1, the resulting score is calculated for each of those 5-tuples by multiplying each fuzzy probability by its corresponding score. As an example, the overall score of the first 5-tuple is found using the following equation (rounded to four significant digits):

$$
\begin{aligned}
0 \times 1 & +0.5333 \times 2+0.2267 \times 3 \\
& +0.6133 \times 4+0.1067 \times 5=3.77 .
\end{aligned}
$$

The scores for all these first 5-tuples are shown in Table 4.

Step 5 of the algorithm requires that the minimum belief for each usable 5-tuple is identified, discarding any case where the belief was zero.

Finally, each value in Table 4 is multiplied by each value in Table 5 and then summed down each column to form an expected score for each supplier on each question. 
TABLE 2: Scores for all suppliers on all attributes of the delivery criterion.

\begin{tabular}{lccccc}
\hline Supplier & On-Time delivery & $\begin{array}{c}\text { Availability of } \\
\text { inventory }\end{array}$ & Shipping accuracy & Return authorization & Overall average \\
\hline$v_{1}:$ Arrow & 3.80 & 3.77 & 3.93 & 3.80 & 3.68 \\
$v_{2}:$ Avnet & 3.69 & 3.63 & 3.90 & 3.30 & 3.72 \\
$v_{3}:$ Future & 3.71 & 3.60 & 3.81 & 3.66 & 3.61 \\
$v_{4}:$ Insight & 3.65 & 3.33 & 3.83 & 3.61 & 3.62 \\
$v_{5}:$ Pioneer & 3.57 & 3.27 & 3.70 & 3.68 & 3.54 \\
$v_{6}:$ TTI & $\mathbf{3 . 8 9}$ & 3.71 & $\mathbf{4 . 0 6}$ & & $\mathbf{3 . 8 3}$ \\
\hline
\end{tabular}

TABLE 3: Steps 1 and 2 of the algorithm applied to survey question 20.

\begin{tabular}{|c|c|c|c|c|c|c|c|c|c|}
\hline & & & & $20 \mathrm{a}$ & $\mathrm{b}$ & c & $\mathrm{d}$ & $\mathrm{e}$ & $\mathrm{f}$ \\
\hline$a 11$ & \multirow{10}{*}{ First partitioned data } & \multirow{5}{*}{ Probability of score } & $1 s$ & 0.0000 & 0.0133 & 0.0405 & 0.0278 & 0.0676 & 0.0000 \\
\hline$a 21$ & & & $2 s$ & 0.0533 & 0.0533 & 0.0270 & 0.0556 & 0.0676 & 0.0448 \\
\hline$a 31$ & & & $3 s$ & 0.2267 & 0.2533 & 0.2568 & 0.2917 & 0.2703 & 0.2388 \\
\hline$a 41$ & & & $4 s$ & 0.6133 & 0.6133 & 0.5811 & 0.4722 & 0.4730 & 0.4627 \\
\hline$a 51$ & & & $5 s$ & 0.1067 & 0.0667 & 0.0946 & 0.1528 & 0.1216 & 0.2537 \\
\hline$\alpha 12$ & & \multirow{5}{*}{$\begin{array}{l}\text { Weight of score } \\
\text { (belief) }\end{array}$} & $1 s$ & 0.0000 & 0.2000 & 0.6300 & 0.4500 & 0.2600 & 0.0000 \\
\hline$\alpha 22$ & & & $2 s$ & 0.1100 & 0.4000 & 0.6000 & 0.4300 & 0.0900 & 0.2400 \\
\hline$\alpha 32$ & & & $3 s$ & 0.3900 & 0.3800 & 0.3400 & 0.1900 & 0.3900 & 0.3300 \\
\hline$\alpha 42$ & & & $4 s$ & 0.3000 & 0.2800 & 0.2400 & 0.3700 & 0.2700 & 0.2500 \\
\hline$\alpha 52$ & & & $5 s$ & 0.2200 & 0.1600 & 0.3300 & 0.3000 & 0.3900 & 0.2600 \\
\hline$a 11$ & \multirow{10}{*}{ Second partitioned data } & \multirow{5}{*}{ Probability of score } & $1 s$ & 0.0400 & 0.0267 & 0.0411 & 0.0143 & 0.0811 & 0.0282 \\
\hline$a 21$ & & & $2 s$ & 0.0800 & 0.0800 & 0.0685 & 0.1286 & 0.0270 & 0.0563 \\
\hline$a 31$ & & & $3 s$ & 0.2133 & 0.2667 & 0.1644 & 0.3000 & 0.2703 & 0.2676 \\
\hline$a 41$ & & & $4 s$ & 0.3600 & 0.4000 & 0.5205 & 0.3143 & 0.4324 & 0.3239 \\
\hline$a 51$ & & & $5 s$ & 0.3067 & 0.2267 & 0.2055 & 0.2429 & 0.1892 & 0.3239 \\
\hline$\alpha 12$ & & \multirow{5}{*}{$\begin{array}{l}\text { Weight of score } \\
\text { (belief) }\end{array}$} & $1 s$ & 0.2500 & 0.3600 & 0.7300 & 0.2000 & 0.3100 & 0.7000 \\
\hline$\alpha 22$ & & & $2 s$ & 0.3400 & 0.3400 & 0.3300 & 0.4400 & 0.1200 & 0.6500 \\
\hline$\alpha 32$ & & & $3 s$ & 0.3800 & 0.4000 & 0.2100 & 0.2800 & 0.3100 & 0.2600 \\
\hline$\alpha 42$ & & & $4 s$ & 0.3500 & 0.3400 & 0.3500 & 0.3900 & 0.3700 & 0.2900 \\
\hline$\alpha 52$ & & & $5 s$ & 0.1900 & 0.1000 & 0.1900 & 0.1900 & 0.1600 & 0.2500 \\
\hline
\end{tabular}

Using the spreadsheet results, the first delivery attribute assessed (on-time delivery) is calculated from the fuzzy probability distributions for the remaining suppliers $\left(Q_{\phi k \nu}\right)$ as

$$
\begin{aligned}
& \frac{j=1}{j=2} \\
Q_{113}=0.63 / 0.04+0.73 / 0.04 & \text { for } s_{113}=\text { Poor }(1) \\
Q_{123}=0.60 / 0.03+0.33 / 0.07 & \text { for } s_{123}=\text { Below Average }(2) \\
Q_{133}=0.34 / 0.26+0.21 / 0.16 & \text { for } s_{133}=\text { Average }(3) \\
Q_{143}=0.24 / 0.58+0.35 / 0.52 & \text { for } s_{143}=\text { Above Average }(4) \\
Q_{153}=0.33 / 0.09+0.19 / 0.21 & \text { for } s_{153}=\text { Excellent }(5) \\
Q_{114}=0.45 / 0.03+0.20 / 0.01 & \text { for } s_{114}=\text { Poor }(1) \\
Q_{124}=0.43 / 0.06+0.44 / 0.13 & \text { for } s_{124}=\text { Below Average }(2) \\
Q_{134}=0.19 / 0.29+0.28 / 0.27 & \text { for } s_{134}=\text { Average }(3)
\end{aligned}
$$

$Q_{144}=0.37 / 0.47+0.35 / 0.52$ for $s_{144}=$ Above Average (4)

$Q_{154}=0.30 / 0.15+0.19 / 0.24$ for $s_{154}=$ Excellent (5)

$Q_{115}=0.26 / 0.07+0.31 / 0.08$ for $s_{115}=\operatorname{Poor}(1)$

$Q_{125}=0.09 / 0.07+0.12 / 0.03$ for $s_{125}=$ Below Average (2)

$Q_{135}=0.39 / 0.27+0.31 / 0.27$ for $s_{135}=$ Average (3)

$Q_{145}=0.27 / 0.47+0.37 / 0.43$ for $s_{145}=$ Above Average (4)

$Q_{155}=0.39 / 0.12+0.16 / 0.19$ for $s_{155}=$ Excellent $(5)$

$Q_{116}=0.00 / 0.00+0.70 / 0.03$ for $s_{116}=\operatorname{Poor}(1)$

$Q_{126}=0.24 / 0.04+0.65 / 0.06$ for $s_{126}=$ Below Average (2)

$Q_{136}=0.33 / 0.24+0.26 / 0.27$ for $s_{136}=$ Average (3)

$Q_{146}=0.25 / 0.46+0.29 / 0.32$ for $s_{146}=$ Above Average (4)

$Q_{156}=0.26 / 0.25+0.25 / 0.32$ for $s_{156}=$ Excellent $(5)$. 
TABLE 4: 5-tuple sums of fuzzy probability combinations for Question 20.

\begin{tabular}{|c|c|c|c|c|c|c|c|}
\hline & & $20 \mathrm{a}$ & $\mathrm{b}$ & $\mathrm{c}$ & $\mathrm{d}$ & $\mathrm{e}$ & $\mathrm{f}$ \\
\hline \multirow{32}{*}{ Raw sums of $n$-tuples } & $a 11 a 21 a 31 a 41 a 51$ & 1.00 & 1.00 & 1.00 & 1.00 & 1.00 & 1.00 \\
\hline & $a 11 a 21 a 31 a 41 a 52$ & 1.20 & 1.16 & 1.11 & 1.09 & 1.07 & 1.07 \\
\hline & $a 11 a 21 a 31 a 42 a 51$ & 0.75 & 0.79 & 0.94 & 0.84 & 0.96 & 0.86 \\
\hline & $a 11 a 21 a 31 a 42 a 52$ & 0.95 & 0.95 & 1.05 & 0.93 & 1.03 & 0.93 \\
\hline & $a 11 a 21 a 32 a 41 a 51$ & 0.99 & 1.01 & 0.91 & 1.01 & 1.00 & 1.03 \\
\hline & $a 11 a 21 a 32 a 41 a 52$ & 1.19 & 1.17 & 1.02 & 1.10 & 1.07 & 1.10 \\
\hline & $a 11 a 21 a 32 a 42 a 51$ & 0.73 & 0.80 & 0.85 & 0.85 & 0.96 & 0.89 \\
\hline & $a 11 a 21 a 32 a 42 a 52$ & 0.97 & 0.97 & 1.09 & 1.01 & 0.99 & 0.94 \\
\hline & $a 11 a 22 a 31 a 41 a 51$ & 1.03 & 1.03 & 1.04 & 1.07 & 0.96 & 1.01 \\
\hline & $a 11 a 22 a 31 a 41 a 52$ & 1.23 & 1.19 & 1.15 & 1.16 & 1.03 & 1.08 \\
\hline & $a 11 a 22 a 31 a 42 a 51$ & 0.77 & 0.81 & 0.98 & 0.92 & 0.92 & 0.87 \\
\hline & $a 11 a 22 a 31 a 42 a 52$ & 0.97 & 0.97 & 1.09 & 1.01 & 0.99 & 0.94 \\
\hline & $a 11 a 22 a 32 a 41 a 51$ & 1.01 & 1.04 & 0.95 & 1.08 & 0.96 & 1.04 \\
\hline & $a 11 a 22 a 32 a 41 a 52$ & 1.21 & 1.20 & 1.06 & 1.17 & 1.03 & 1.11 \\
\hline & $a 11 a 22 a 32 a 42 a 51$ & 0.76 & 0.83 & 0.89 & 0.92 & 0.92 & 0.90 \\
\hline & $a 11 a 22 a 32 a 42 a 52$ & 0.96 & 0.99 & 1.00 & 1.01 & 0.99 & 0.97 \\
\hline & $a 12 a 21 a 31 a 41 a 51$ & 1.04 & 1.01 & 1.00 & 0.99 & 1.01 & 1.03 \\
\hline & $a 12 a 21 a 31 a 41 a 52$ & 1.24 & 1.17 & 1.11 & 1.08 & 1.08 & 1.10 \\
\hline & $a 12 a 21 a 31 a 42 a 51$ & 0.79 & 0.80 & 0.94 & 0.83 & 0.97 & 0.89 \\
\hline & $a 12 a 21 a 31 a 42 a 52$ & 0.99 & 0.96 & 1.05 & 0.92 & 1.04 & 0.96 \\
\hline & $a 12 a 21 a 32 a 41 a 51$ & 1.03 & 1.03 & 0.91 & 0.99 & 1.01 & 1.06 \\
\hline & $a 12 a 21 a 32 a 41 a 52$ & 1.23 & 1.19 & 1.02 & 1.08 & 1.08 & 1.13 \\
\hline & $a 12 a 21 a 32 a 42 a 51$ & 0.77 & 0.81 & 0.85 & 0.84 & 0.97 & 0.92 \\
\hline & $a 12 a 21 a 32 a 42 a 52$ & 1.01 & 0.99 & 1.09 & 0.99 & 1.00 & 0.97 \\
\hline & $a 12 a 22 a 31 a 41 a 51$ & 1.07 & 1.04 & 1.04 & 1.06 & 0.97 & 1.04 \\
\hline & $a 12 a 22 a 31 a 41 a 52$ & 1.27 & 1.20 & 1.15 & 1.15 & 1.04 & 1.11 \\
\hline & $a 12 a 22 a 31 a 42 a 51$ & 0.81 & 0.83 & 0.98 & 0.90 & 0.93 & 0.90 \\
\hline & $a 12 a 22 a 31 a 42 a 52$ & 1.01 & 0.99 & 1.09 & 0.99 & 1.00 & 0.97 \\
\hline & $a 12 a 22 a 32 a 41 a 51$ & 1.05 & 1.05 & 0.95 & 1.07 & 0.97 & 1.07 \\
\hline & $a 12 a 22 a 32 a 41 a 52$ & 1.25 & 1.21 & 1.06 & 1.16 & 1.04 & 1.14 \\
\hline & $a 12 a 22 a 32 a 42 a 51$ & 0.80 & 0.84 & 0.89 & 0.91 & 0.93 & 0.93 \\
\hline & $a 12 a 22 a 32 a 42 a 52$ & 1.00 & 1.00 & 1.00 & 1.00 & 1.00 & 1.00 \\
\hline
\end{tabular}

\section{Results and Discussion}

3.1. Results. The fuzzy probabilities from the respondents for the six suppliers are found by Step 3 of the algorithm and result in four fuzzy probability (summation to 1.0) combinations for $v_{3} ; 8$ combinations for $v_{4} ; 5$ combinations for $v_{5}$; and 2 combinations for $v_{6}$. The results for the six suppliers in this spreadsheet example are as shown in Table 6.

The question then becomes whether this fuzzy set-based model is useful in identifying supplier performance and indeed is a better supplier selection approach. One measure for this is the mean absolute percent deviation of these values from a simple averaging of the 150 example responses, which amounts to 0.35 percent in this example. This indicates that the algorithm as illustrated with survey data is statistically robust.

The expected values derived from the fuzzy probability scores and the simple average scores are consistent when rounded to two significant digits. Thus, the data selection and partitioning process from Step 0 of the algorithm did not perturb the numerical results unduly.

The fuzzy probability approach shows $v_{6}$ as the best for on-time delivery and accuracy of the shipment with $v_{1}$ second best, but $v_{1}$ is best for inventory availability and authorization of returns with $v_{6}$ second best. With an overall average score for these suppliers differing by only 0.01 , a decision maker might be inclined to rate both Arrow and TTI as preferred suppliers.

As another basic comparison, a simple averaging of all respondent input is considered as shown in Table 7.

In contrast to results from both the fuzzy set-based model and the simple average of the partitioned dataset, when using a simple average method across all data, the rankings are fairly inconsistent except for $v_{6}$ which scored the highest on every delivery attribute, thus ranking as $\# 1$. The rankings for the other suppliers are not obvious. 
TABLE 5: Fuzzy probabilities for Question 20 multiplied by associated scores (1-5) and summed for each usable 5-tuple.

\begin{tabular}{|c|c|c|c|c|c|c|c|}
\hline & & $20 a$ & $\mathrm{~b}$ & c & $\mathrm{d}$ & $\mathrm{e}$ & $\mathrm{f}$ \\
\hline & $a 11 a 21 a 31 a 41 a 51$ & 3.7733 & 3.6667 & 3.6622 & 3.6667 & 3.5135 & 3.9254 \\
\hline & $a 11 a 21 a 31 a 41 a 52$ & & & & & & \\
\hline & $a 11 a 21 a 31 a 42 a 51$ & & & & & & \\
\hline & $a 11 a 21 a 31 a 42 a 52$ & & & & & & \\
\hline & $a 11 a 21 a 32 a 41 a 51$ & & & & 3.6917 & 3.5135 & \\
\hline & $a 11 a 21 a 32 a 41 a 52$ & & & & & & \\
\hline & $a 11 a 21 a 32 a 42 a 51$ & & & & & & \\
\hline & $a 11 a 21 a 32 a 42 a 52$ & & & & 3.6313 & & \\
\hline & $a 11 a 22 a 31 a 41 a 51$ & & & & & & \\
\hline & $a 11 a 22 a 31 a 41 a 52$ & & & & & & \\
\hline & $a 11 a 22 a 31 a 42 a 51$ & & & & & & \\
\hline & $a 11 a 22 a 31 a 42 a 52$ & & & & 3.6313 & & \\
\hline & $a 11 a 22 a 32 a 41 a 51$ & & & & & & \\
\hline & $a 11 a 22 a 32 a 41 a 52$ & & & & & & \\
\hline Fuzzy probabilities times & $a 11 a 22 a 32 a 42 a 51$ & & & & & & \\
\hline values 1 through 5 & $a 11 a 22 a 32 a 42 a 52$ & & & 3.7803 & & & \\
\hline & $a 12 a 21 a 31 a 41 a 51$ & & & 3.6627 & & & \\
\hline & $a 12 a 21 a 31 a 41 a 52$ & & & & & & \\
\hline & $a 12 a 21 a 31 a 42 a 51$ & & & & & & \\
\hline & $a 12 a 21 a 31 a 42 a 52$ & & & & & & \\
\hline & $a 12 a 21 a 32 a 41 a 51$ & & & & 3.6782 & & \\
\hline & $a 12 a 21 a 32 a 41 a 52$ & & & & & & \\
\hline & $a 12 a 21 a 32 a 42 a 51$ & & & & & & \\
\hline & $a 12 a 21 a 32 a 42 a 52$ & & & & 3.6179 & 3.6216 & \\
\hline & $a 12 a 22 a 31 a 41 a 51$ & & & & & & \\
\hline & $a 12 a 22 a 31 a 41 a 52$ & & & & & & \\
\hline & $a 12 a 22 a 31 a 42 a 51$ & & & & & & \\
\hline & $a 12 a 22 a 31 a 42 a 52$ & & & & 3.6179 & 3.6216 & \\
\hline & $a 12 a 22 a 32 a 41 a 51$ & & & & & & \\
\hline & $a 12 a 22 a 32 a 41 a 52$ & & & & & & \\
\hline & $a 12 a 22 a 32 a 42 a 51$ & & & & & & \\
\hline & $a 12 a 22 a 32 a 42 a 52$ & 3.8133 & 3.7200 & 3.7808 & 3.6429 & 3.6216 & 3.8592 \\
\hline
\end{tabular}

For example, $v_{3}$ was second best for on-time delivery and inventory availability, but weakest of all suppliers with respect to return authorization. The $v_{2}$ criterion was second for accuracy of shipping and return authorization, but otherwise inconsistent. The $v_{5}$ criterion was the least competitive for ontime delivery, availability of inventory, and shipping accuracy but was competitive for return authorization. The $v_{1}$ criterion ranked fourth in on-time performance and managed only a third place on the other attributes.

Therefore, using all available respondent data for every supplier does not yield as clear a set of results as does the fuzzy algorithm. The fuzzy set-based model resolves these types of ambiguity derived from customer perceptions and close scores within $[1,5]$.

3.2. Discussion. The fuzzy set-based approach has an advantage not observed in simple averages or a typical scoring approach. Each customer describes the importance to them of each of the various supplier attributes, which can be compared against the cumulative fuzzy probabilities of each supplier to perform to expectations, often revealing an apparent contradiction when compared with each customer's stated preferred supplier. For example, customer "B2573" states a preference for supplier $v_{2}$ when supplier $v_{6}$ should better meet this customer's needs along the lines of delivery performance. This customer ranks supplier $v_{6} 5$ th out of 6 , effectively excluding supplier $v_{6}$ from its primary business. As observed in the literature, fuzzy set-based models can handle this type of decision maker uncertainty and the ambiguity of data provided. The algorithm presented herein with illustrative application adds further support to this conclusion.

The algorithm incorporates beliefs into the determination of the scores, so by the approach detailed, the weight is inherent to the score and avoids the potential bias of weighting 
TABLE 6: Minimum beliefs for Question 20 for each usable 5-tuple.

\begin{tabular}{|c|c|c|c|c|c|c|c|}
\hline & & $20 \mathrm{a}$ & $\mathrm{b}$ & c & $\mathrm{d}$ & e & $\mathrm{f}$ \\
\hline \multirow{32}{*}{$\begin{array}{l}\text { Fuzzy probabilities times } \\
\text { values } 1 \text { through } 5\end{array}$} & $a 11 a 21 a 31 a 41 a 51$ & 0.1100 & 0.1600 & 0.2400 & 0.1900 & 0.0900 & 0.2400 \\
\hline & $a 11 a 21 a 31 a 41 a 52$ & & & & & & \\
\hline & $a 11 a 21 a 31 a 42 a 51$ & & & & & & \\
\hline & $a 11 a 21 a 31 a 42 a 52$ & & & & & & \\
\hline & $a 11 a 21 a 32 a 41 a 51$ & & & & 0.2800 & 0.0900 & \\
\hline & $a 11 a 21 a 32 a 41 a 52$ & & & & & & \\
\hline & $a 11 a 21 a 32 a 42 a 51$ & & & & & & \\
\hline & $a 11 a 21 a 32 a 42 a 52$ & & & & 0.1900 & & \\
\hline & $a 11 a 22 a 31 a 41 a 51$ & & & & & & \\
\hline & $a 11 a 22 a 31 a 41 a 52$ & & & & & & \\
\hline & $a 11 a 22 a 31 a 42 a 51$ & & & & & & \\
\hline & $a 11 a 22 a 31 a 42 a 52$ & & & & 0.1900 & & \\
\hline & $a 11 a 22 a 32 a 41 a 51$ & & & & & & \\
\hline & $a 11 a 22 a 32 a 41 a 52$ & & & & & & \\
\hline & $a 11 a 22 a 32 a 42 a 51$ & & & & & & \\
\hline & $a 11 a 22 a 32 a 42 a 52$ & & & 0.1900 & & & \\
\hline & $a 12 a 21 a 31 a 41 a 51$ & & & 0.2400 & & & \\
\hline & $a 12 a 21 a 31 a 41 a 52$ & & & & & & \\
\hline & $a 12 a 21 a 31 a 42 a 51$ & & & & & & \\
\hline & $a 12 a 21 a 31 a 42 a 52$ & & & & & & \\
\hline & $a 12 a 21 a 32 a 41 a 51$ & & & & 0.2000 & & \\
\hline & $a 12 a 21 a 32 a 41 a 52$ & & & & & & \\
\hline & $a 12 a 21 a 32 a 42 a 51$ & & & & & & \\
\hline & $a 12 a 21 a 32 a 42 a 52$ & & & & 0.1900 & 0.1200 & \\
\hline & $a 12 a 22 a 31 a 41 a 51$ & & & & & & \\
\hline & $a 12 a 22 a 31 a 41 a 52$ & & & & & & \\
\hline & $a 12 a 22 a 31 a 42 a 51$ & & & & & & \\
\hline & $a 12 a 22 a 31 a 42 a 52$ & & & & 0.1900 & 0.1200 & \\
\hline & $a 12 a 22 a 32 a 41 a 51$ & & & & & & \\
\hline & $a 12 a 22 a 32 a 41 a 52$ & & & & & & \\
\hline & $a 12 a 22 a 32 a 42 a 51$ & & & & & & \\
\hline & $a 12 a 22 a 32 a 42 a 52$ & 0.1900 & 0.1000 & 0.1900 & 0.1900 & 0.1200 & 0.2500 \\
\hline
\end{tabular}

and determining a score after seeing the average score for each supplier. It is this type of ambiguity and potential bias in scoring models that the fuzzy probability model eliminates.

The algorithm utilizes a partitioning of the dataset prior to execution of the fuzzy set machinations. The partitioning for ease of presentation and spreadsheet application was confined to two equal sets. This study was restricted to five scores and two datasets partly to limit complexity to 32 unique combinations per supplier per attribute, a problem that could be hard-coded into a spreadsheet fairly easily. The algorithm is not restrictive and can handle any number of criteria, attributes, decision maker input, and partitioning without loss of generality.

The spreadsheet itself is a unique contribution. While the algorithm has been accepted in a more generalized form, no further modeling was conducted on large databases due to limitations caused by the size of any realistic supplier selection decision making process. The spreadsheet provided easily interpreted input into the algorithmic format. Also, the use of the survey instrument allowed representative input from an extensive number (150 viable respondents) with whom a one-to-one assessment and measure of beliefs would have been difficult to manage, especially as the survey respondents were based internationally.

It is worthwhile to consider the fuzzy application as applied to the largest available dataset. Whereas the dataset in use was pared down to 150 total respondents (75 per partition), the original dataset includes some 406 individual responses, although they vary greatly in the percentage of the survey questions completed. Table 8 shows the results of the fuzzy method applied to this approximately 2.7 times larger dataset. 
TABLE 7: Averaged operational parameter data for the six suppliers.

\begin{tabular}{lccccccccc}
\hline Supplier & $n$ & $\begin{array}{c}\text { On-Time } \\
\text { delivery }\end{array}$ & $n$ & $\begin{array}{c}\text { Inventory } \\
\text { availability }\end{array}$ & $n$ & $\begin{array}{c}\text { Shipping } \\
\text { accuracy }\end{array}$ & $n$ & RMA & Average \\
\hline$\nu_{1}:$ Arrow & 361 & 3.6953 & 362 & 3.6353 & 359 & 3.8719 & 334 & $\mathbf{3 . 6 3 7 7}$ & 3.71 \\
$\nu_{2}:$ Avnet & $\mathbf{3 7 5}$ & 3.6773 & $\mathbf{3 7 7}$ & 3.6220 & $\mathbf{3 7 4}$ & 3.9251 & $\mathbf{3 5 6}$ & $\mathbf{3 . 6 4 0 4}$ & 3.72 \\
$\nu_{3}:$ Future & 347 & 3.7666 & 347 & 3.6455 & 344 & 3.8517 & 310 & 3.3129 & 3.64 \\
$\nu_{4}:$ Insight & 282 & 3.6631 & 287 & 3.3171 & 284 & 3.8627 & 245 & 3.5918 & 3.61 \\
$\nu_{5}:$ Pioneer & 298 & 3.5872 & 300 & 3.0333 & 295 & 3.7492 & 265 & 3.5509 & 3.48 \\
$\nu_{6}:$ TTI & 281 & $\mathbf{3 . 9 2 8 8}$ & 291 & $\mathbf{3 . 7 2 5 1}$ & 283 & $\mathbf{4 . 0 2 1 2}$ & 256 & $\mathbf{3 . 6 5 2 3}$ & $\mathbf{3 . 8 3}$ \\
\hline
\end{tabular}

TABLE 8: Fuzzy scores for all suppliers on all attributes of the delivery criterion, dataset of all 406 respondents.

\begin{tabular}{|c|c|c|c|c|c|}
\hline Supplier & On-Time delivery & $\begin{array}{l}\text { Availability of } \\
\text { inventory }\end{array}$ & Shipping accuracy & Return authorization & Overall average \\
\hline$v_{1}:$ Arrow & 3.70 & 3.64 & 3.88 & 3.63 & 3.71 \\
\hline$v_{2}:$ Avnet & 3.68 & 3.59 & 3.91 & 3.55 & 3.68 \\
\hline$v_{3}:$ Future & 3.77 & 3.66 & 3.86 & 3.31 & 3.65 \\
\hline$v_{4}:$ Insight & 3.66 & 3.33 & 3.86 & 3.57 & 3.61 \\
\hline$v_{5}:$ Pioneer & 3.59 & 3.30 & 3.75 & 3.53 & 3.54 \\
\hline$v_{6}:$ TTI & 3.93 & 3.73 & 4.02 & 3.65 & 3.83 \\
\hline
\end{tabular}

Of note is that this result from the data superset conforms even more closely to the average operational parameter data from Table 7, with resulting rankings substantially similar, except for the RMA category. However, when averaged into overall supplier ranking, a different set of preferences emerges from the subtle differences between simple average scores and fuzzy criteria scores. The same supplier, TTI, is chosen first, but this time Arrow outranks Avnet for second place, supporting the decision made when using the fuzzy algorithm on the smaller data subset and reinforcing the notion that a fuzzy approach yields different results that consistently capture and use belief to handle ambiguity in the data. Removing the incomplete responses to create the aforementioned data subset (as was used to create Table 7) merely served to enhance this effect, to the extent that Arrow challenges TTI for first place and becomes a plausible option as a supplier of first choice.

A major benefit of using survey data for this decision system is the ease of data accumulation and modeling. The application shows that a typical industry survey can be adapted, which allows a company to employ the fuzzy setbased model whenever canned data are available. This aspect alone could allow companies to engage in supplier selection evaluations and potentially improve the number that evaluate suppliers from the approximately 50 percent that have been measured to do so [1].

The closeness of the survey data when statistically analyzed is not a surprise given the use of the survey and adjustments for belief functions. Of support to the fuzzy set-based approach is that the results were similar, while an opportunity for a company following this approach would be to adjust the design of the survey instrument to more directly obtain respondent beliefs, rather than rely on the assumption that total spending corresponds directly to belief.
Finally, some consideration of complexity is in order. The fuzzy algorithm presented is not, itself, a significant source of computational complexity and should operate with suitably low complexity on any large dataset that can nevertheless fit in a modern spreadsheet file. However, as the dataset increases in size, so does the size of the data partitions, until there begin to be algorithm advantages to splitting the dataset into more than two partitions. However, every increase in the number of data partitions causes a geometric increase in the complexity, not of the algorithm, but of the organization of the dataset. In this study, a brute force method of dataset organization was applied that manually broke the dataset into two partitions. Because the data in the questions consisted of responses on a Likert scale, this study resulted in an organizational complexity best illustrated by Table 4 . Every possible combination of responses within a question/partition combination must be calculated and considered, so any increase in the number of partitions (or in the size of the question scale; from a 5-point Likert scale to a 7-point Likert scale, for example) adds a huge amount of additional set-up complexity to the process. This added complexity amounts to a "price" paid for additional fuzzy performance, because a dataset of arbitrarily large size could still be addressed using only the two-partition approach shown in this paper's example. However, additional performance from the fuzzy algorithm can be achieved in larger datasets by paying the complexity cost of increased partitions.

At some point of increased complexity (partition and/or question scale), the organization of the dataset must be handled programmatically, because it becomes untenable to manually organize the evaluation of the question/partition ntuples as was done in this study. It will be a topic of further study to develop methods of scaling up this complexity smoothly to match the opportunities presented by larger 
datasets. As it is, arbitrarily large datasets can be handled effectively using the presented method.

\section{Conclusions}

The fuzzy set-based method for ranking suppliers is shown to be more robust than other methods. Traditional scoring methods fail to adequately consider the ambiguity in data belief among opinion holders. Fuzzy set theory is equipped to handle these complexities. The spreadsheet application is a considerable benefit of this model, especially for small to mid-size companies (SMOs). SMOs lack the resources for expensive data analysis systems or consultants. SMOs can readily gather or repurpose large sets of data using a survey similar to the one used in this application and can apply this algorithm to obtain the benefit of using fuzzy logic to evaluate their suppliers. Furthermore, this fuzzy set-based model utilizes basic computational tools of a spreadsheet that any organization can apply with little or no additional cost.

The fact that the algorithmic process can be adapted to use such a database is a benefit to any company. All combinations must be considered where fuzzy probabilities for the outcomes (Excellent, Above Average, etc.) sum 100\%. The use of standard statistical probability by dividing the quantity seen of each score by the total number of responses always provides one "default" case for each set of partitioned data. Then, the spreadsheet calculates all possible combinations of the fuzzy probabilities, per the algorithm. A limitation to be addressed is redesign of the survey instrument to allow for directly obtaining belief functions for supplier membership in qualitatively defined variables such as excellent, good, fair, and so forth and allowing membership not to be crisply defined as 1.0.

As was discussed in Section 2.6, the fuzzy algorithm, in theory, is not overly complex, but in practice the resulting decision support system can become complex in proportion to the dataset size. There are two primary factors in this. The first is that, for the example spreadsheet illustration, only two partitions were created (per Step 0 of the algorithm). For 150 sets of respondent data, this puts a relatively small amount of data in each partition but more importantly creates a relatively small number of possible fuzzy combinations of scores and partitions. Even when all 406 responses are evenly partitioned, the result is manageable datasets. But, increasing to significantly large datasets would make using only two partitions suboptimal. Increasing the number of data partitions addresses this but increases the combinatorial testing for fuzzy probabilities summing 1.0 (Steps 3 and 4 of the algorithm). When dealing with a survey dataset where at least one combination is forced into a sum of 1.0 (the default case described above), this becomes less of a consideration than when fuzzy beliefs are provided resulting in potential inconsistencies of judgments by the decision makers. Still, the spreadsheet model can address numerous partitions without loss of functionality. The second problem is that (at present) the combinations are not programmatically generated but are instead the result of visual inspection (or manually created automation for each different dataset) for all fuzzy probabilities. This brute forcing of the data is being addressed through development of a network-type of interface by which the spreadsheet will be populated directly from the dataset into combinations, regardless of the number of partitioned sets. Thus, while larger datasets increase the complexity of the spreadsheet-based DSS, the algorithm itself is fully able to handle datasets of any size with negligible increases in computational power.

Future research on this topic will seek to integrate other criteria and available data-not just delivery-specific data. As in this study, by using other survey responses involving criteria beyond price, delivery, and quality, it becomes possible to make specific recommendations by evaluating suppliers using criteria not usually considered. Also, an aforementioned improvement in the ease by which users may scale up complexity for ever larger datasets is an area for further research and development.

\section{Conflict of Interests}

The authors declare that there is no conflict of interests regarding the publication of this paper.

\section{References}

[1] P. M. Simpson, J. A. Siguaw, and S. C. White, "Measuring the performance of suppliers: an analysis of evaluation processes," Journal of Supply Chain Management, vol. 38, no. 1, pp. 29-41, 2002.

[2] L. Vijayvagy, "Decision framework for supplier selection through multi criteria evaluation models in supply chain," International Journal of Management \& Innovation, vol. 4, no. 2, pp. 16-28, 2012.

[3] R. M. Monczka, K. J. Petersen, R. B. Handfield, and G. L. Ragatz, "Success factors in strategic supplier alliances: the buying company perspective," Decision Sciences, vol. 29, no. 3, pp. 553573,1998

[4] G. Wang, S. H. Huang, and J. P. Dismukes, "Product-driven supply chain selection using integrated multi-criteria decisionmaking methodology," International Journal of Production Economics, vol. 91, no. 1, pp. 1-15, 2004.

[5] K. S. Bhutta and F. Huq, "Supplier selection problem: a comparison of the total cost of ownership and analytic hierarchy process approaches," Supply Chain Management, vol. 7, no. 3, pp. 126$135,2002$.

[6] R. Handfield, S. V. Walton, R. Sroufe, and S. A. Melnyk, "Applying environmental criteria to supplier assessment: a study in the application of the Analytical Hierarchy Process," European Journal of Operational Research, vol. 141, no. 1, pp. 70-87, 2002.

[7] H. J. Einhorn and R. M. Hogarth, "Ambiguity and uncertainty in probabilistic inference," Psychological Review, vol. 92, no. 4, pp. 433-461, 1985.

[8] D. Kahneman and A. Tversky, "Prospect theory: an analysis of decision under risk," Econometrica, vol. 47, no. 2, pp. 263-292, 1979.

[9] G. Shafer, A Mathematical Theory of Evidence, vol. 1, Princeton University Press, Princeton, NJ, USA, 1976.

[10] J. Yen, "Generalizing the Dempster-Shafer theory to fuzzy sets," IEEE Transactions on Systems, Man, and Cybernetics, vol. 20, no. 3, pp. 559-570, 1990. 
[11] L. A. Zadeh, "A simple view of the Dempster-Shafer theory of evidence and its implication for the rule of combination," $A I$ Magazine, vol. 7, no. 2, pp. 85-90, 1986.

[12] A. D. Korvin and M. F. Shipley, "Dempster-Shafer-based approach to compromise decision making with multiattributes applied to product selection," IEEE Transactions on Engineering Management, vol. 40, no. 1, pp. 60-67, 1993.

[13] R. E. Bellman and L. A. Zadeh, "Decision-making in a fuzzy environment," Management Science, vol.17, no. 4, pp. B141-B164, 1970.

[14] V. Jain, S. Wadhwa, and S. G. Deshmukh, "Supplier selection using fuzzy association rules mining approach," International Journal of Production Research, vol. 45, no. 6, pp. 1323-1353, 2007.

[15] R. R. Yager, "Toward a general theory of reasoning with uncertainty. I: nonspecificity and fuzziness," International Journal of Intelligent Systems, vol. 1, no. 1, pp. 45-67, 1986.

[16] G. J. Klir and B. Yuan, Fuzzy Sets and Fuzzy Logic, Prentice Hall, Upper Saddle River, NJ, USA, 1995.

[17] R. R. Yager and V. Kreinovich, "Entropy conserving probability transforms and the entailment principle," Fuzzy Sets and Systems, vol. 158, no. 12, pp. 1397-1405, 2007.

[18] A. Zebda, "The investigation of cost variances: a fuzzy set theory approach," Decision Sciences, vol. 15, no. 3, pp. 359-388, 1984.

[19] A. Hadi-Vencheh and M. Niazi-Motlagh, "An improved voting analytic hierarchy process-data envelopment analysis methodology for suppliers selection," International Journal of Computer Integrated Manufacturing, vol. 24, no. 3, pp. 189-197, 2011.

[20] A. Guneri and A. Kuzu, "Supplier selection by using a fuzzy approach in just-in-time: a case study," International Journal of Computer Integrated Manufacturing, vol. 22, no. 8, pp. 774-783, 2009.

[21] F.-H. F. Liu and H. L. Hai, "The voting analytic hierarchy process method for selecting supplier," International Journal of Production Economics, vol. 97, no. 3, pp. 308-317, 2005.

[22] D. Park and H. A. Krishnan, "Supplier selection practices among small firms in the United States: testing three models," Journal of Small Business Management, vol. 39, no. 3, pp. 259271, 2001.

[23] N. Hirakubo and M. Kublin, "The relative importance of supplier selection criteria: the case of electronic components procurement in Japan," Journal of Supply Chain Management, vol. 34, no. 2, pp. 19-24, 1998.

[24] C. A. Weber, J. R. Current, and W. C. Benton, "Vendor selection criteria and methods," European Journal of Operational Research, vol. 50, no. 1, pp. 2-18, 1991.

[25] L. M. Ellram, "The supplier selection decision in strategic," Journal of Purchasing and Materials Management, vol. 26, no. 4, pp. 8-14, 1990.

[26] R. Verma and M. E. Pullman, "An analysis of the supplier selection process," Omega, vol. 26, no. 6, pp. 739-750, 1998.

[27] Z. Degraeve and F. Roodhooft, "A smarter way to buy," Harvard Business Review, vol. 79, no. 6, pp. 22-145, 2001.

[28] Z. Degraeve and F. Roodhooft, "Effectively selecting suppliers using total cost of ownership," Journal of Supply Chain Management, vol. 35, no. 1, pp. 5-10, 1999.

[29] B. Vahdani and M. Zandieh, "Selecting suppliers using a new fuzzy multiple criteria decision model: the fuzzy balancing and ranking method," International Journal of Production Research, vol. 48, no. 18 , pp. 5307-5326, 2010.
[30] B. Liu, "Fuzzy criterion models for inventory systems with partial backorders," Annals of Operations Research, vol. 87, pp. 117-126, 1999.

[31] K. Das, T. K. Roy, and M. Maiti, "Buyer-seller fuzzy inventory model for a deteriorating item with discount," International Journal of Systems Science: Principles and Applications of Systems and Integration, vol. 35, no. 8, pp. 457-466, 2004.

[32] J. Usenik and M. Bogataj, "A fuzzy set approach for a locationinventory model," Transportation Planning and Technology, vol. 28, no. 6, pp. 447-464, 2005.

[33] J. C.-H. Pan and M.-F. Yang, "Integrated inventory models with fuzzy annual demand and fuzzy production rate in a supply chain," International Journal of Production Research, vol. 46, no. 3, pp. 753-770, 2008.

[34] Y. Kara, H. Gökçen, and Y. Atasagun, "Balancing parallel assembly lines with precise and fuzzy goals," International Journal of Production Research, vol. 48, no. 6, pp. 1685-1703, 2010.

[35] T.-F. Liang, "Integrating production-transportation planning decision with fuzzy multiple goals in supply chains," International Journal of Production Research, vol. 46, no. 6, pp. 14771494, 2008.

[36] W.-H. Tsai and S.-J. Hung, "A fuzzy goal programming approach for green supply chain optimisation under activity-based costing and performance evaluation with a value-chain structure," International Journal of Production Research, vol. 47, no. 18, pp. 4991-5017, 2009.

[37] M.-H. Shu and H.-C. Wu, "Measuring the manufacturing process yield based on fuzzy data," International Journal of Production Research, vol. 48, no. 6, pp. 1627-1638, 2010.

[38] F. T. S. Chan, N. Kumar, M. K. Tiwari, H. C. W. Lau, and K. L. Choy, "Global supplier selection: a fuzzy-AHP approach," International Journal of Production Research, vol. 46, no. 14, pp. 3825-3857, 2008.

[39] M. Bevilacqua and A. Petroni, "From traditional purchasing to supplier management: a fuzzy logic-based approach to supplier selection," International Journal of Logistics, vol. 5, no. 3, pp. 235-255, 2002.

[40] M. Y. Bayrak, N. Çelebi, and H. Takin, "A fuzzy approach method for supplier selection," Production Planning and Control, vol. 18, no. 1, pp. 54-63, 2007.

[41] M. Sevkli, "An application of the fuzzy ELECTRE method for supplier selection," International Journal of Production Research, vol. 48, no. 12, pp. 3393-3405, 2010.

[42] L. A. Zadeh, "Generalized theory of uncertainty (GTU)principal concepts and ideas," Computational Statistics \& Data Analysis, vol. 51, no. 1, pp. 15-46, 2006.

[43] D. Dubois and H. Prade, "Systems of linear fuzzy constraints," Fuzzy Sets and Systems, vol. 3, no. 1, pp. 37-48, 1980.

[44] A. N. S. Freeling, "Fuzzy sets and decision analysis," IEEE Transactions on Systems, Man and Cybernetics, vol. 10, no. 7, pp. 341-354, 1980.

[45] R. R. Yager, "On some new classes of implication operators and their role in approximate reasoning," Information Sciences, vol. 167, no. 1-4, pp. 193-216, 2004.

[46] A. Kaufmann and M. Gupta, An Introduction to Fuzzy Sets Arithmetic, Nosfrand Reinhold, New York, NY, USA, 1985.

[47] G. J. Klir and T. A. Folger, Fuzzy Sets, Uncertainty, and Information, 1988.

[48] L. A. Zadeh, "Fuzzy sets," Information and Control, vol. 8, pp. 338-353, 1965. 
[49] L. A. Zadeh, "Fuzzy logic and approximate reasoning," Synthese, vol. 30, no. 3-4, pp. 407-428, 1975.

[50] M. M. Gupta, R. K. Ragade, and R. R. Yager, Advances in Fuzzy Set Theory and Applications, North-Holland, New York, NY, USA, 1979.

[51] M. F. Shipley and G. L. Stading, "Supplier selection decisions: a fuzzy logic model based on quality aspects of delivery," in Advances in Computational Intelligence, vol. 300 of Communications in Computer and Information Science, pp. 1-9, Springer, Berlin, Germany, 2012. 

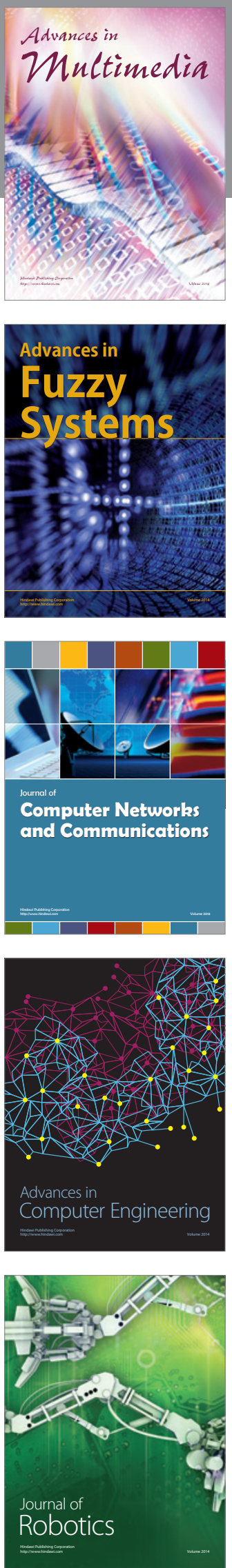

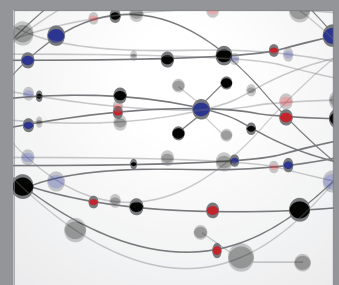

The Scientific World Journal
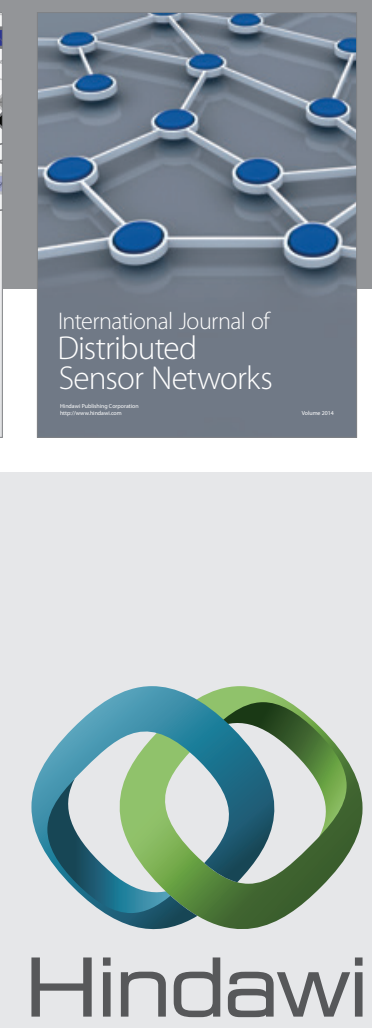

Submit your manuscripts at

http://www.hindawi.com
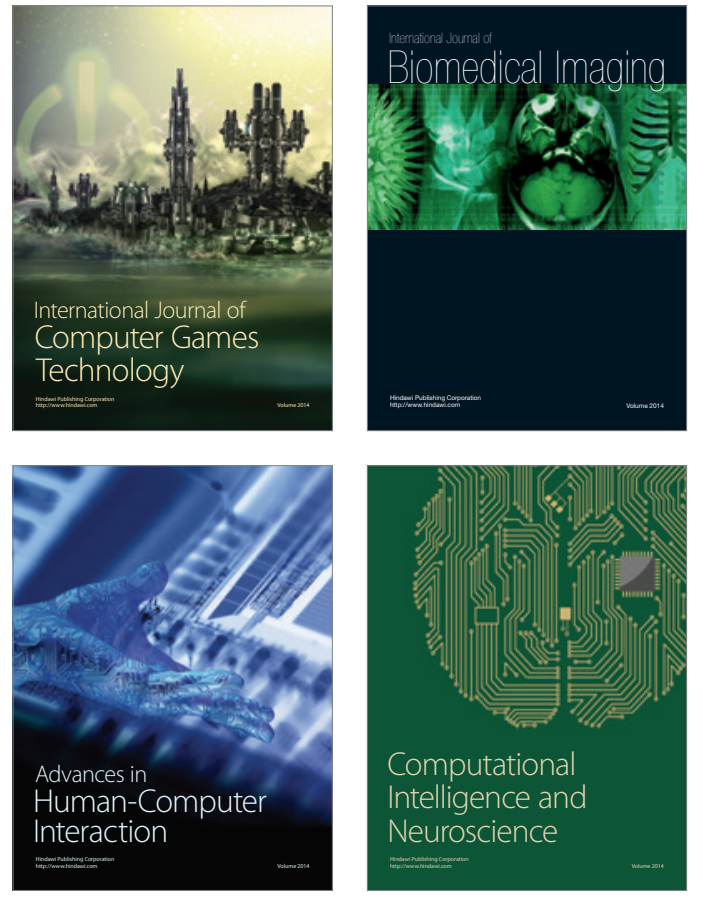
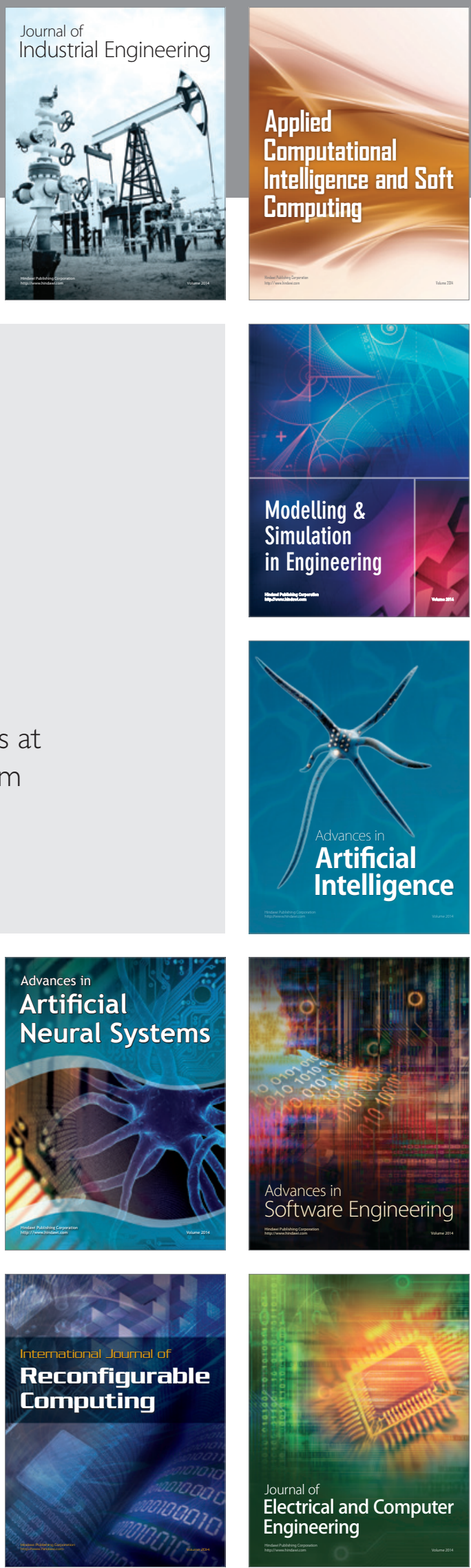